\title{
Treatment of dyslipidemia in the elderly patients
}

\begin{abstract}
The manifestations of atherosclerotic disease (coronary artery disease, cerebrovascular and/or peripheral disease) may have even more deleterious repercussions in elderly. In the elderly, although the number of coronary events decreases with age (relative risk), the number of patients who would benefit from "prevention" (treatment) annually, per 1000 individuals, tends to be higher than in young individuals (absolute risk). Advanced age alone should not be considered as a limiting factor for therapeutic intervention in cases of dyslipidemia. The analysis of life expectancy and quality of life are extremely important. Disabling diseases that compromise life expectancy, such as: severe heart failure, advanced cerebrovascular disease, dementia, neoplasms and frailty, when present, limit the possibility of any type of preventive cardiovascular treatment. Another limiting factor is the frequent previous use of a large number of medications, due to the possibility of increasing unfavorable drug interactions. Combined strategies of physical activity, diet, tobacco and alcohol use, adherence to medication, screening, vaccination and cognitive and mental health have been proposed as specific preventive recommendations for each decade. The most common dyslipidemia in this age group is secondary caused by pathologies such as diabetes mellitus, obesity, renal failure and also by the use of drugs that alter the lipid profile. When prescribing lipid-lowering drugs for individuals over the age of 65 years it is necessary to remember that there are numerous changes in the "aged" organism and, therefore, treatment should be started with lower doses than those usually prescribed for young adults; the increase should be gradual and analyzed in each case individually. Statins and fibrates are the lipid-lowering drugs that have shown better tolerability in the elderly and are therefore the first choice medications. PCSK9 inhibitor is most probably indicated in Familial Hypercholesterolemia patients.
\end{abstract}

Keywords: elderly patient, geriatrics, cholesterol, lipids, dyslipidemia, cardiovascular risk factor
Volume 4 Issue 3 - 2020

\author{
Maysa Seabra Cendoroglo,' Anita LR \\ Saldanha, ${ }^{2}$ Andreia Assis Loures Vale, ${ }^{2}$ \\ Lisia Marcílio Rabelo, ${ }^{3}$ Ana Paula Pantoja \\ Margeotto, ${ }^{4}$ Tania Leme da Rocha Martinez, ${ }^{2}$ \\ Andre L Gasparoto 4 \\ 'Department of Geriatrics, Federal University of São Paulo \\ (UNIFESP), São Paulo, Brazil \\ ${ }^{2}$ Nephrology Department, BP - A Beneficência Portuguesa de \\ São Paulo, São Paulo, Brazil \\ ${ }^{3}$ Department of Family Health, Federal University of Bahia \\ (UFBA), Salvador, Brazil \\ ${ }^{4}$ Intensive Care Unit, BP - A Beneficência Portuguesa de São \\ Paulo, São Paulo, Brazil
}

Correspondence: Tania Leme da Rocha Martinez, BP - A Beneficência Portuguesa de São Paulo, Rua Comandante Ismael Guilherme, 358 - Jardim Lusitânia 0403।-I 20 - São Paulo - SP, Brazil,Tel 55 II 98323-9863, Fax 55 || 3842-3789, Email taar@uol.com.br

Received: June 18, 2020 | Published: June 29, 2020
Abbreviations: BMI - body mass index; CAD - coronary artery disease; HDL-c - high density lipoprotein cholesterol; LDL-c - low density lipoprotein cholesterol; PCSK9 - proprotein convertase subtilisin/kexin Type 9; TG - triglyceride

\section{Introduction}

According to the World Health Organization, all individuals from industrialized nations over 65 years old are considered elderly patients; the developing countries this limit falls to 60 years of age. ${ }^{1}$ In Brazil, the Brazilian Institute of Geography and Statistics (IBGE), ${ }^{2}$ points out that the number of elderly patients in 2017 exceeded 30.2 million and the expectation is that by 2060 , this number will rise to 73 million aged 60 years or older, being considered an old country in 2032..$^{1,3}$ In 1987 , Kalache et al. ${ }^{1}$ already estimated that the increase in the Brazilian population will be around 15 times between 1950 and 2025, which will make Brazil conquer the position of fifth or sixth elderly population in the world in absolute terms. ${ }^{3}$ The increase in the Brazilian elderly population draws attention to the need to adopt measures aimed primarily at offering a better quality of life to individuals belonging to this age group. Overall, the observation that life expectancy has been increasing and also healthy life expectancy has increased by $8 \%$ (from 59 to 63 years). ${ }^{1}$ The manifestations of atherosclerotic disease (coronary artery disease - CAD, cerebrovascular and/or peripheral disease) may have even more deleterious repercussions in elderly patients. Most often they imply in a long period of hospitalization or home restriction to the bed, predisposing the patient to other pathologies of difficult recovery in this age group, not to mention the large number of fatal cases and long-term disability.
It is worth remembering that the risk for CAD increases with aging being the first cause of mortality in this age group. The preponderance of coronary events and the high prevalence of total cholesterol levels higher than $200 \mathrm{mg} / \mathrm{dl}$ are relevant facts to be considered. ${ }^{4-8}$ In the Framingham Study (analysis of 30 years of observation), the classical risk factors for coronary heart disease remained equally important even in the age group between 65-90 years. ${ }^{6}$ In the Cardiovascular Health Study, elevated levels of high density lipoprotein (HDL-c) cholesterol, low density lipoprotein (LDL-c) cholesterol, and body mass index (BMI) were associated with increased longevity. Among those who survived to the age of 90 , those with the worst cardiovascular profile (high blood pressure, LDL-c, glycemia and BMI and low HDL-c) were less likely to remain free of cardiovascular disease, cognitive impairment and disability. ${ }^{9}$ However, in the BELFRAIL study (prospective, observational, population-based), 567 individuals aged 80 years and over, traditional risk factors were not associated with mortality but frailty was a strong risk factor. ${ }^{10}$ In the elderly patients, although the number of coronary events decreases with age (relative risk), the number of patients who would benefit from "prevention" (treatment) annually, per 1000 individuals, tends to be higher than in young individuals (absolute risk).

Hypertriglyceridemia should not be devalued during lipid profile evaluation. Many authors already consider it as an independent risk factor for CAD. ${ }^{8}$ The association with low HDL-c levels makes this risk even greater. Moreover, we must not forget that high triglyceride levels can lead to acute pancreatitis. However, in 930 long-lived elderly patients (mean age $=94$ years) in a Chinese cohort, after 5 years of follow-up, for every $1-\mathrm{mmol} / \mathrm{L}$ of triglycerides (TGs) increase there was a cognitive decline of $20 \%$, daily life activities and 
frailty. Associations with all-cause mortality and TG concentrations were associated in this study. ${ }^{11}$ Advanced age alone should not be considered as a limiting factor for therapeutic intervention in cases of dyslipidemia. The analysis of life expectancy and quality of life are extremely important. Disabling diseases that compromise life expectancy, such as: severe heart failure, advanced cerebrovascular disease, dementia, neoplasms and frailty, when present, limit the possibility of any type of preventive cardiovascular treatment. Another limiting factor is the frequent previous use of a large number of medications, due to the possibility of increasing unfavorable drug interactions. ${ }^{12}$ Combined strategies of physical activity, diet, tobacco and alcohol use, adherence to medication, screening, vaccination and cognitive and mental health have been proposed as specific preventive recommendations for each decade. ${ }^{13}$

In a study by Kastner et al. ${ }^{14}$ the subgroup analysis of elderly patients with diabetes, depression, or cardiovascular disease, coexisting with chronic obstructive pulmonary disease and heart failure showed that they can benefit from combined strategies. According to the Consensus, ${ }^{15-20}$ dietary orientation is extremely important and should be very judicious, maintaining the caloric and vitamin intake of the elderly patients. General recommendations such as acquisition and maintenance of ideal weight, regular physical activity, smoking cessation, among others, prevail. We must keep in mind the greatest difficulty of adherence to non-pharmacological treatment in this group of patients, since our intervention will be done in habits that persist for a long time; if we are facing primary prevention and this fact is detected, we should prolong the non-pharmacological treatment phase (up to 6 months).

The reference laboratory values for the elderly patients are the same as those considered for younger age groups. The orientation towards a more aggressive approach to secondary prevention is also maintained in this group, but in the case of primary prevention the evidence of benefits is less clear. ${ }^{21,22}$ The most common dyslipidemia in this age group is secondary (Update of the Brazilian Guideline for Dyslipidemias and Prevention of Atherosclerosis - 2017) ${ }^{23}$ caused by pathologies such as diabetes mellitus, obesity, renal failure and also by the use of drugs that alter the lipid profile. Therefore, before starting pharmacological treatment of the dyslipemic elderly patients, this should be thoroughly investigated. When prescribing lipidlowering drugs for individuals over the age of 65 years it is necessary to remember that there are numerous changes in the "aged" organism and, therefore, treatment should be started with lower doses than those usually prescribed for young adults (in our service we usually start treatment with half of these doses); the increase should be gradual and analyzed in each case individually.

Statins (degree of recommendation IIa, level of evidence B) and fibrates (degree of recommendation IIb, level of evidence D) are the lipid-lowering drugs that have shown better tolerability in the elderly patients and are therefore the drugs of first choice ${ }^{15-20}$ Side effects are very uncommon and should be investigated individually in each patient. The Scandinavian Simvastatin Survival Study -4S (4S, $1994)^{24}$ showed, despite this not being main objective, that regular and permanent administration of a statin (simvastatin) in the subgroup of elderly patients ( 518 patients aged between 60 and 70 years) reduced the risk of total mortality by $34 \%$ and decreased by $43 \%$ the risk of coronary events; there have been no reports of discontinuation of therapy due to intolerance and/or serious adverse effects.

In the PROSPER study (2002), ${ }^{25} 5,804$ elderly patients aged 70 to 82 years $(52 \%$ of women) with history or risk factors for cardiovascular disease were randomly allocated to one group treated with $40 \mathrm{mg}$ pravastatin/day and another placebo group. Pravastatin decreased $34 \%$ of LDL-col concentration and reduced the incidence of events to 408 in the treated group compared with 473 in the placebo group. There was also a reduction in mortality due to coronary heart disease $(24 \%)$ and risk of non-fatal myocardial infarction, but there was no significant effect on cognitive function or disability. Some serious adverse effects have also been reported in both groups but there have been no cases of rhabdomyolysis. There were reports of 36 cases of myalgia in the pravastatin group and 32 in placebo. When the maximum doses of statin are not sufficient to achieve the targets, ezetimibe (degree of recommendation IIb, level of evidence B) ${ }^{26}$ may be associated with ezetimibe. In the IMPROVE-IT study (ClinicalTrials. gov identifier NCT00202878) the combination of simvastatin with ezetimibe resulted in a $20 \%$ reduction in the incidence of events in those $\geq 75$ years compared with a $3 \%$ reduction in the $<75$-yearold group. ${ }^{26}$ PCSK9 inhibitor is most probably indicated in familial Hypercholesterolemia patients. ${ }^{27}$ In conclusion, we must approach the elderly patient always remembering that their life expectancy today is higher and that it is our duty to prolong it whenever possible, without, however, harming their quality of life and always adjusting their balanced and vitamin caloric needs satisfactorily.

\section{Acknowledgments}

None.

\section{Conflicts of interest}

The author declares there is no conflict of interest.

\section{Funding}

None.

\section{References}

\section{WHO - World Health Organization. 2019.}

2. OPAS - Organização Panamericana de Saúde. 2018.

3. Kalache A, Veras RP, Ramos LR. O envelhecimento da população mundial: um desafio novo. Rev Saúde Pública. 1987;21(3):200-210.

4. Stamler J, Wentworth D, Neaton JD. Is relationship between serum cholesterol and risk of premature death from coronary heart disease continuous and graded? Findings on 356,222 primary screenees of the Multiple Risk Factor Intervention Trial (MRFIT). JAMA. 1986;256(20):2823-2828.

5. Gordon DJ, Rifkind BM. Treating high blood cholesterol in the older patient. Am J Cardiol. 1989;63(16):48-52.

6. The Multiple Risk Factor Intervention Trial Research Group. Mortality rates after 10.5 years for participants in the Multiple Risk Factor Intervention Trial. Findings related to a priori hypothesis of the trial. JAMA. 1990;263(13):1795-1801.

7. Massa KHC, Pabayo R, Lebrão ML, et al. Environmental factors and cardiovascular diseases: the association of income inequality and green spaces in elderly residents of São Paulo, Brazil. BMJ Open. 2016;6(9):e011850.

8. Massa KHC, Duarte YAO, Chiavegatto Filho ADP. Análise da prevalência de doenças cardiovasculares e fatores associados em idosos, 2000-2010. Ciência \& Saúde Coletiva. 2019;24(1):105-114.

9. Odden MC, Rawlings AM, Arnold AM, et al. Patterns of cardiovascular risk factors in old age and survival and health status at 90. J Gerontol A Biol Sci Med Sci. 2020;glaa043. 
10. Vaes B, Depoortere D, Van Pottelbergh G, et al. Association between traditional cardiovascular risk factors and mortality in the oldest old: untangling the role of frailty. BMC Geriatr. 2017;17(1):234.

11. Lv YB, Mao C, Gao X, et al. Triglycerides paradox among the oldest old: “The Lower the Better?” J Am Geriatr Soc. 2019;67(4):741-748.

12. Gordon T, Kannel WB, Castelli WP, et al. Lipoproteins, cardiovascular disease, and death. The Framingham study. Arch Intern Med. 1981;141(9):1128-1131.

13. Hajat C, Selwyn A, Harris M, et al. Preventive interventions for the second half of life: a systematic review. Am J Health Promot. 2018;32(4):11221139 .

14. Kastner M, Cardoso R, Lai Y, et al. Effectiveness of interventions for managing multiple high-burden chronic diseases in older adults: a systematic review and meta-analysis. CMAJ. 2018;190(34):E1004E1012.

15. Roberts CGP, Guallar E, Rodriguez A. Efficacy and safety of statin monotherapy in older adults: a meta-analysis. J Gerontol A Biol Sci Med Sci. 2007;62(8):879-887.

16. Wilson PWF, Polonsky TS, Miedema MD, et al. Systematic review for the 2018. AHA/ACC/AACVPR/AAPA/ABC/ACPM/ADA/AGS/APhA/ ASPC/NLA/PCNA. Guideline on the management of blood cholesterol. A report of the American College of Cardiology/American Heart Association Task Force on Clinical Practice Guidelines. Circulation. 2019;139:e1144-e1161.

17. Tobe SW, Stone JA, Anderson T, et al. Canadian Cardiovascular Harmonized National Guidelines Endeavour (C-CHANGE) guideline for the prevention and management of cardiovascular disease in primary care: 2018 update. CMAJ. 2018;190(40):E1192-E1206.

18. Précoma DB, Oliveira GMM, Simão AF, et al. Updated cardiovascular prevention guideline of the Brazilian Society of Cardiology - 2019. Arq Bras Cardiol. 2019;113(4):787-891.
19. Feitosa-Filho GS, Peixoto JM, Pinheiro JES, et al. Updated geriatric cardiology guidelines of the Brazilian Society of Cardiology - 2019. Arq Bras Cardiol. 2019;112(5):649-705.

20. Mach F, Baigent C, Catapano AL, et al. 2019 ESC/EAS guidelines for the management of dyslipidaemias: lipid modification to reduce cardiovascular risk. The task force for the management of dyslipidaemias of the European Society of Cardiology (ESC) and European Atherosclerosis Society (EAS). Eur Heart J. 2020;41(1):111-188.

21. Mortensen MB, Falk E. Primary prevention with statins in the elderly. $J$ Am Coll Cardiol. 2018;71(1):85-94.

22. Strandberg TE. Role of statin therapy in primary prevention of cardiovascular disease in elderly patients. Curr Atheroscler Rep. 2019;21(8):28.

23. Faludi AA, Izar MCO, Saraiva JFK, et al. Atualização da Diretriz Brasileira de Dislipidemias e Prevenção da Aterosclerose - 2017. Arq Bras Cardiol. 2017;109(2 Suppl 1):1-76.

24. Scandinavian Simvastatin Survival Study Group. Randomised trial of cholesterol lowering in 4444 patients with coronary heart disease: the Scandinavian Simvastatin Survival Study (4S). Lancet. 1994;344(8934):1383-1389.

25. Shepherd J, Blauw GJ, Murphy MB, et al. Pravastatin in elderly individuals at risk of vascular disease (PROSPER): a randomised controlled trial. Lancet. 2002;360(9346):1623-1630.

26. Yandrapalli S, Gupta S, Andries G, et al. Drug therapy of dyslipidemia in the elderly. Drugs Aging. 2019;36(4):321-340.

27. Foundation of Familial Hypercholesterolemia (FH). 2019. 